\title{
How to Design Empowering Work-based Learning Settings to Foster Students' Competence Development
}

\author{
Louisa Feldmann \\ Institute of Work Science, \\ Ruhr-Universität Bochum, Germany
}

\author{
Nicole Sprafke \\ Institute of Work Science, \\ Ruhr-Universität Bochum, Germany
}

\begin{abstract}
Equipping students with competences which enhance employability is a central aim of higher education that can be reached through work-based learning (WBL) settings. However, the research in higher education on individual and contextual enabling factors of WBL settings is still fragmented. In order to contribute to a systematic design approach, we widen the higher education perspective towards organisational studies, especially the construct of "empowerment". This approach systematically captures the characteristics of enabling working environments, and also emphasises the individual's perception of being empowered. In this paper, we deduce eight influencing factors for competence development, which are, concerning the student's perspective, meaningfulness, selfdetermination, impact, and self-efficacy, and, regarding the university, respectively practical partner perspective, facilitative leadership, sociopolitical support, access to information and resources, and opportunities for mobility and growth. Based on these factors, we infer recommendations for designing WBL settings which enhance employability.
\end{abstract}

\section{Introduction}

Employees are looking for employable graduates, which means that the latter are cognitive as well as socially and personally highly skilled and trained for work [1]. Thereby, organisations expect universities to play a key role in generating work-ready graduates, which also meshes with one of the key aims of higher education: employability. Fostering employability means to enable graduates to cope with high complexity and the dynamic of modern working environments [2]. Thus, aside from education, universities aim at preparing students for the vocational world.

Since employability, respectively its underlying competences, cannot be taught, learned or developed in the one-situational context of formal learning, students need to be exposed to the challenges of the vocational world in advance of their entrance. This implies that students need to become competent in dealing with the changing environmental demands and those of knowledge economy and society [3]. A common approach to generally address these outcomes are work-based learning (WBL) settings [4]. They improve graduates' human capital, and thus, their productivity in the vocational world.

However, WBL settings in higher education enabling learning through work or at work - differ broadly depending on the practical partners, academic supervisors and learning individual involved [5] [6]. Consequently, the development of employability enhancing competences in WBL settings varies as well. Even though current research addresses both individual and contextual enabling factors of these settings, design implications still remain fragmented [4]. This may be traced back to the general search for 'best practices' rather than for a systematic profound approach considering the different impact factors on employability enhancing competences.

However, if we widen the perspective, it becomes apparent that organisational research already provides a multitude of well-founded approaches to develop competence. The field of organisational learning particularly deals with designing working conditions that contain the potential to purposefully influence human resource capacities which cannot be determined and directly controlled [7]. In this instance, the concept of empowerment has gained considerable attention, since it combines the contextual and the individual perspective, i.e. it systematically captures the characteristics of enabling working environments, and also emphasises the individual's perception of being empowered [8]. Therefore, we assume that findings from empowerment research can enrich the search for a systematic approach to designing WBL settings and raise the question: What can higher education research learn from organisational studies on empowerment to foster students' employability enhancing competences in WBL settings?

To provide an answer to this question, we first elaborate on employability and its linkage to the development of competence. Based on current research on competences developed in WBL settings and by framing this in social cognitive theory, it 
becomes apparent that two factors influence the development of employability enhancing competences, namely the individual him- or herself and the working conditions [9]. We extract eight influencing factors from empowerment research for creating empowering learning conditions in WBL settings that address these two perspectives. By means of these eight factors, we derive, moreover, propositions for integrating empowering WBL settings in higher education as well as further research implications.

\section{Enhancing employability in WBL settings}

\subsection{Linkages between employability and competences}

A broadly acknowledged definition of employability in higher education research is provided by Yorke, who defines employability as "a set of achievements - skills, understandings and personal attributes - that make graduates more likely to gain employment and be successful in their chosen occupations, which benefits themselves, the workforce, the community and the economy" [10]. Even if there is a clear reference to employment, he points out that employability is not about gaining a job after graduation, but rather the capacity to act in a specific employment and to be able to change it. This implies a lifelong development of competences and is in line with Harvey's view that the emphasis should be less on 'employ', but more on 'ability', and therefore, on "developing critical, reflective abilities, with a view to empowering and enhancing the learner" [11].

This view is also emphasised in organisation research. In this field, employability refers to the "continuous fulfilling, acquiring, or creating of work through the optimal use of one's competences", which are needed to act and solve work-related problems, as well as to constantly adapt to changes and insecurity [12]. Hence, this definition focuses on cross-situational acting in the vocational world, though it ignores the fact that competences should not only be used, but can also be enhanced in working scenarios. Moreover, it recognises employability as an ongoing process. This is in line with graduates' perception of employability, because for them, work-related learning in higher education was "driven by the need to secure a particular job and progress within one's current position" [13].

The definitions above reveal that competences are inherent in employability, and hence, fostering employability seems intrinsically tied to the development of competences. Therefore, we propose a competence-based approach to employability, i.e. to focus on employability enhancing competences.
However, there are various definitions of competence in higher education research. Following the argumentation of Stoof, Martens, van Merriënboer, and Bastiaens, it is not possible to find or formulate a general definition and distinction of competence to related terminologies, such as competency, key-competence, capacity, capability, ability, and skill [14] [15]. Thus, there is a need to define it according to the specific context in which competence is used.

Taking into consideration the view on employability mentioned above, we define employability enhancing competences as crosssituational action and problem-solving capabilities. This definition is in concordance with organisational behaviour and behavioural psychology, which refer to competence as the successful and self-organised coping with changing requirements in ambiguous situations which is a result of problem-solving skills, knowledge and abilities [16]. Hence, being and staying employable implies, as has already been elaborated in the definitions of employability discussed, that such competences must be continuously developed and enhanced in working scenarios. Arising from this, competence development in the working context refers to activities that are related to both the organisation and the individual, thus, it is an integrative approach of development [12] [17].

\subsection{Competence development in WBL settings}

There has been a broad discussion about students' competence development as a result of higher education. The relation of general skills as well as competences needed in the world of work to be and stay employable have gained increasing attention. The reason for this is that WBL settings bridge the gap between academic knowledge and competences acquired through academia and those needed at work. Since a central aim of higher education is employability, although universities can only provide formal education, it is absolutely necessary to offer sufficient WBL opportunities to enable students to cope with the changing environmental demands and the demands of the knowledge economy and society.

At first glance, WBL settings offer students the possibility of comparing what they have learned with the reality and complexity of the vocational world [18]. Moreover, they provide students with practical experience of applying academic concepts, deepen their understanding of an organisation, enable personal development and the acquisition of additional skills, and promote their career prospects [19]. Recent studies have shown that internships, as the prevalent WBL setting, enable the creation of knowledge, the transfer of academic knowledge and concepts to the work context, and the enhancement 
of self-efficacy, as well as the ability to manage, lead and work in teams [1] [15] [20] [21]. Additionally, internships improve social skills, such as communication, and professional skills [22] [23]. To sum it up, WBL settings appear as an opportunity to foster competences that improve students' crosssituational capacity to act in the vocational world, and thus, their employability.

In spite of this, it cannot be expected or guaranteed that pure participation in a WBL setting is sufficient for a development of employability enhancing competences. There are two factors that influence this development highly, namely the individual him- or herself and the working conditions [4]. This implies that these two factors must be taken into consideration when designing and implementing WBL settings which improve competence.

A theoretical basis for explicating competence development in working settings is provided by Bandura's social cognitive theory [24]. According to Bandura, the level of self-perceived employability is highly related to the individual self-efficacy [9]. The social cognitive theory explains the individual capability to act on the basis of one's own perception of competence. According to this theory, behaviour is the result of two types of expectations an individual has about him- or herself: self-efficacy and outcome expectations. Self-efficacy is defined as the belief that one is capable of performing in a certain manner, consequently, a self-appraisal, to reach a specific goal related to a person's belief in his or her own competence [25]. Outcome expectations can be defined as the judgment of the likely consequences of a certain behaviour. This theory refers to the fact that people, believing and trusting in their own competences, have a high selfefficacy and belief in a successful outcome, and thus, a higher probability of reaching their desired goals [24]. The reason, therefore, is that self-efficacy enables learning through self-regulatory processes, such as goal setting, as well as self-evaluation and monitoring. Being self-confident about doing something successfully leads to the actual capability to do it, as self-efficacy determines people's behaviour, their effort, their perseverance, their choices, and thus, their performance [24]. The main learning mechanisms and influencing factors of selfefficacy are vicarious experiences, enactive mastery, social persuasion and physiological arousal [26].

Following this notion, working conditions that are widely settled by the practical partner and also the university, respectively the academic supervisor, have to support the self-efficacy of the student. In particular, a working environment that is characterized by a high task identity, an adequate degree of freedom and responsibility, as well as task variety and diversity, and fault tolerance promotes the development of self-efficacy and, therefore, of competences [27] [28]. Furthermore, tasks that aim at problem-solving seem beneficial as well as social support from peers and supervisors, whereat participation is a reinforcing factor [27] [28]. As a result, universities must offer sufficient WBL opportunities that comply with such criteria in order to facilitate employability with a competence-based approach. Universities are thus faced with the challenge to foster the link between themselves and the world of work.

At the same time, WBL settings differ broadly depending on the parties involved. Consequently, the development of competences in WBL settings which enhance employability varies as well, depending on the two already named factors, the individual and the working conditions which are set by the parties involved. Therefore, there is a need to shed more light onto the empowering learning conditions from both influencing factors of competence development, namely the individual him- or herself and the working conditions.

\section{Impact of empowering WBL settings on employability enhancing competences in higher education}

\subsection{Developing competences in WBL settings through empowering learning conditions}

As outlined above, working environments that are connected to enhancing self-efficacy by providing supportive job characteristics are advantageous for competence development. In organisational studies, these insights have resulted in extensive research on empowerment as a framework for organisational change, learning and involvement [8]. The value of the broadly acknowledged concept of empowerment derives from the combination of two perspectives: social-structural and psychological empowerment [8]. These perspectives combine the considerations of the job characteristics model and Bandura's work on self-efficacy [9] [26]. While structural empowerment focuses on designing structures, policies and practices, psychological empowerment represents a micro orientation towards employees' perceptions of empowerment, i.e. on the state of perceiving that one has control over his or her work [8]. Therefore, contextual and individual factors, influencing learning behaviour and performance, are integrated into one systematic concept.

Studies show that empowerment initiatives in organisations are positively related to employees' workplace learning and individual learning behaviour [29] [30]. Van Grinsven and Visser particularly argue that empowerment affects secondorder learning, since it enhances employees' creativity, reflection, development of new solutions, and flexibility to adapt to current circumstances [31]. Moreover, empowerment leads to an active 
orientation towards work enabling proactive behaviour, commitment and innovative problem solutions [32] [33] [34]. Such exemplary results reflect a form of competence development that is founded in social cognitive theory [9] [24]. But what makes empowerment particularly effective for competence development?

Following Al Zahrani, employees are more concerned with workplace learning when they recognise the value of their work goal and purpose, believe in their capabilities to perform, have choice and autonomy in initiating and regulating actions, and influence different outcomes at work [29]. This reflects the four-dimensional framework of psychological empowerment, including meaning, self-efficacy, self-determination, and impact [32] [35]. Meaning refers to congruence between the individual's work role and his or her goals, beliefs and values, and includes, therefore, an identification with the work task. Self-determination describes the individual's sense of having choice in initiating and regulating actions, which also reflects having autonomy, e.g. in making decisions about work methods. Impact, at first, seems similar, but, in contrast to self-determination, this dimension does not refer to an individual's sense of control over his or her work, but the feeling of control regarding aggregated outcomes. Thus, impact describes the individual perception of being able to influence strategic, administrative or operating outcomes in the work context, such as the work group or department. Self-efficacy refers to an individual's belief in performing an activity with skill. All in all, these perceptions are regarded as a motivational vehicle [35].

Different studies show that these critical perceptions of learning in work processes, and, thus, competence development, are fundamentally impacted by the social and structural working environment. A first influencing factor, in this instance, is leadership, particularly forms of transformational or facilitative leadership [e.g. 36, 37]. Empowering behaviours of leaders are especially connected to coaching people, informing them, leading by example, showing concern about and interacting with others, and fostering participative decision-making [38]. Moreover, Amy shows that emotional intelligent communication displays an empowering leadership behaviour that facilitates individual learning [39]. This refers not only to establishing emotional connections and customizing responses, but also includes an informal style of communication that creates an open and trusting atmosphere. Amundsen and Martinsen highlight further supportive behaviours of leaders that promote subordinates' empowerment [40]. They show that delegation, co-ordination, information sharing, encouragement of initiative and goal focus, efficacy support, and inspirational communication and guidance influence employees' opportunities and motivation to perform activities autonomously, as well as their continuous learning.

The working environment also plays a decisive role in enabling learning in the work place. The influencing factors of the working environment are reflected by social-structural empowerment. Particularly the support of peers and access to information, resources and opportunities evidentially create a working setting that fosters a state of empowerment [41]. Access to support is connected to feedback and guidance that can be emotional (caring guidance), appraising (comparison with others), informational (advice, data), or instrumental [42]. Foss, Klein, Kor, and Mahoney argue that individuals who are equipped with information, resources and the freedom to experiment are more likely to be aware of changes, be creative, speak up about their observations and ideas, and learn and take action in an entrepreneurial way [43]. Access to information mostly refers to organisational policies and goals, values, data, and technical knowledge, since such information is necessary to attain expertise and to actively participate in decisionmaking processes [44]. In a similar manner, access to resources like time and materials necessary for good performance are influential [44]. Moreover, opportunities for mobility and growth are critical for designing an empowering work environment. This is determined by access to challenges and rewards, as well as the chance to participate on committees [42].

Thus, social-structural and psychological empowerment are different constructs that both enable individual learning. However, they are not completely independent, but interdependent.

Based on the elaborated findings, one can assume that students will cope more effectively, respectively learn to cope, with uncertain situations and with the needs for continuous renewal, thus becoming more employable if empowering conditions are created in WBL settings as presented in Figure 1. Eight influencing factors for competence development in WBL settings can especially be derived from the findings explicated above:

- Meaningfulness of work

- Self-determination at work

- Impact on (collective) work results

- Perception of self-efficacy from experiences

- Facilitative leadership behaviours

- Socio-political support at work

- Equipment with information and resources

- Opportunities for mobility and growth 


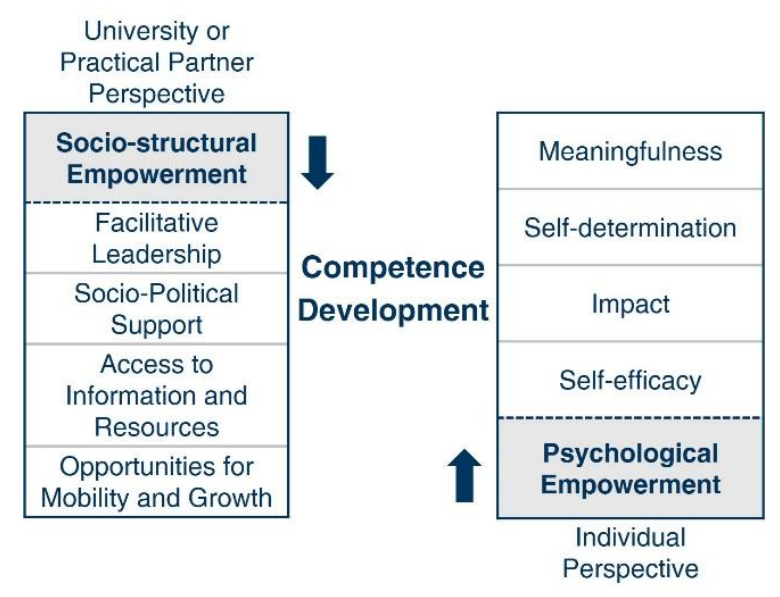

Figure 1. Influencing factors on students' competence development in WBL settings (Source: Authors' own illustration)

Figure 1 shows that the student's competence development is influenced from two perspectives, the university or practical partner and the individual. The university and the practical partner can empower a WBL setting through socio-structural factors as forms of transformational or facilitative leadership. Moreover, providing support, the access to information and resources, as well as opportunities for mobility and growth create an empowering WBL setting. Notwithstanding the above, the degree of competence development is highly influenced by psychological empowerment, thus, the individual's perception of being empowered. This perspective is highly determined by the individual's self-efficacy. Additionally, the perceived congruence between the individual's work role and his or her goals, thus meaningfulness of the work, as well as selfdetermination at the work place and the impact on work results are influencing factors on the student's competence development in WBL settings.

\subsection{Propositions for integrating empowering WBL settings in higher education}

In the following, we use the WBL setting of internships in order to elaborate exemplarily the integration of empowering learning conditions. It seems necessary to refer to a setting that is broadly acknowledged and theoretically well-researched as well as commonly embedded in the curriculum in order to enhance students' employability. Nevertheless, it is possible to derive recommendations for empowering learning conditions for other WBL settings, such as simulations and project weeks.

Concerning competence development in internships, higher education research generally focuses on three main aspects: preparation through higher education and, in the phase of doing the internship, the accompaniment and the supervision through the practical partner and the university. Due to this, we not only put forward in the following propositions for integrating empowering internships in higher education based on the eight influencing factors derived, but also relate them to the three aspects just mentioned.

With regard to the eight influencing empowerment factors identified for competence development, one measure to make students feel empowered, and thereby become self-regulated, is to support their belief that success is largely dependent on his or her own competences, thus is under their own control [45]. This goes hand in hand with the influencing factor of self-determination at work. That can be fostered in higher education through a preparation of the WBL setting by training or case studies, hence problem-based learning, where students make enactive mastery experience they can draw on afterwards. Students learn, thereby, selfdirected learning, to structure knowledge in order to use it in the vocational world, decision-making and problem-solving processes, as well as relevant reasoning and, at the same time, their motivation to learn and their social skills are enhanced [46]. Cooperative internships are one particular form of doing this. Internships are a co-operative education experience, where universities become an involved party in the internship through mentoring, preparing and accompanying, thus, the mostly informal learning experience in the vocational world is supported and accompanied by the formal setting und supervision of the university. The classroombased education is then combined and mutually agreed with the internships, which means that students work alone or in groups in a given timeframe for an organisation on a particular and complex project or problem that aims at a concrete outcome for the organisation [46]. Thereby, students have a high impact on the work results. The problems topic must be theoretically discussed in the accompanying course so that students are exposed to a complex scenario; for example, a strategic project could be created that is of direct value to the practical partner and the intern, providing the freedom to experiment. This is supported by Balta, Coughlan and Hobson, who find in their quantitative study with undergraduate students from the fields of Business, Engineering and Information Systems that work experiences being highly related to course content enable the transfer of the academically acquired knowledge to practice, and enhances the self-confidence and motivation [1]. For the latter, inferences can be drawn to the meaning of the WBL setting to the individual, thus the perception, as important and personally meaningful. To sum it up, co-operative internships do not only create broad opportunities for mobility and growth, but can also improve the meaning of the work perceived by the students. 
Generally, the interns' perception of work as important and personally meaningful can be fostered when they write a progress report on areas of improvement and present findings and recommendations for the supervisor at the conclusion of the internship. This framing implies that interns are provided with a supervisor from the organisation. The supervisor should manage all aspects of the internship, for example, structure, recruiting and evaluation, but is also responsible and accountable for equipping the intern with information and resources. Broadly speaking, supervisors at the workplace have a direct impact on students by defining contextual work factors and by sharing a firm's vision. Their style of leadership affects the individual actions greatly. Beginning with a written job description, the organisational culture and policies, as well as expectations and management processes should be discussed. By establishing a clear vision of the internship aims and defining the steps, respectively specific work assignments, required to achieve it, the supervisor motivates and inspires the student highly. Further facilitation, and thereby learning, can be achieved through showing students how to solve work problems on their own. This can be supported by mentoring. By asking questions, clarifying expectations, attenuating uncertainty, and strengthening self-confidence, mentoring not only provides the necessary support at work, but also enhances self-efficacy. Especially for the latter, students need to receive positive feedback, have role models and get suggestions for improvement [24]. Thus, students should be matched with an executive as a mentor throughout the internship. Since universities cannot ensure that, an academic supportive supervisor should also be provided who accompanies the internship. Bullock et al. support this by stressing the high importance that students have the possibility to discuss possible risks with informed persons or the institutes of higher education and call for appropriate strategies of institutes of higher education to encourage and support students in their learning during the work placement [22].

Another approach to integrate empowering conditions in the curriculum is community-based learning, which generally takes place in every WBL setting. Students become members of the community of the vocational world for a predetermined time, which leads to an enhancement in social and personal competences as well as multicultural appreciation and community engagement [47]. Nevertheless, this can be improved. De Leng et al. showed in two case studies with a mixed-method approach that groups of students using a collective elearning model during a WBL setting enhanced their ability of critical thinking on basic science concepts [48]. The use of a collective e-learning model during their internships, particularly if there are cohort groups of interns, seems, therefore, suitable to ensure the accompaniment provided by peers and the academic supervisor. This enhances the students' ability to think critically and reflect.

To sum it up, WBL settings which are not embedded and accompanied by the university also provide benefits, but they are no substitute for a well-supported internship. Therefore, making internships obligatory in the curriculum does not seem to be a sufficient way to enhance students' employability.

Table 1 shows a systematisation of the recommendations already elaborated in the two phases of the internship, preparation and participation, respectively accomplishment, related to the eight empowering learning conditions.

Table 1. Systematisation of propositions for integrating empowering WBL settings related to the influencing factors deduced (Source: Authors' own illustration)

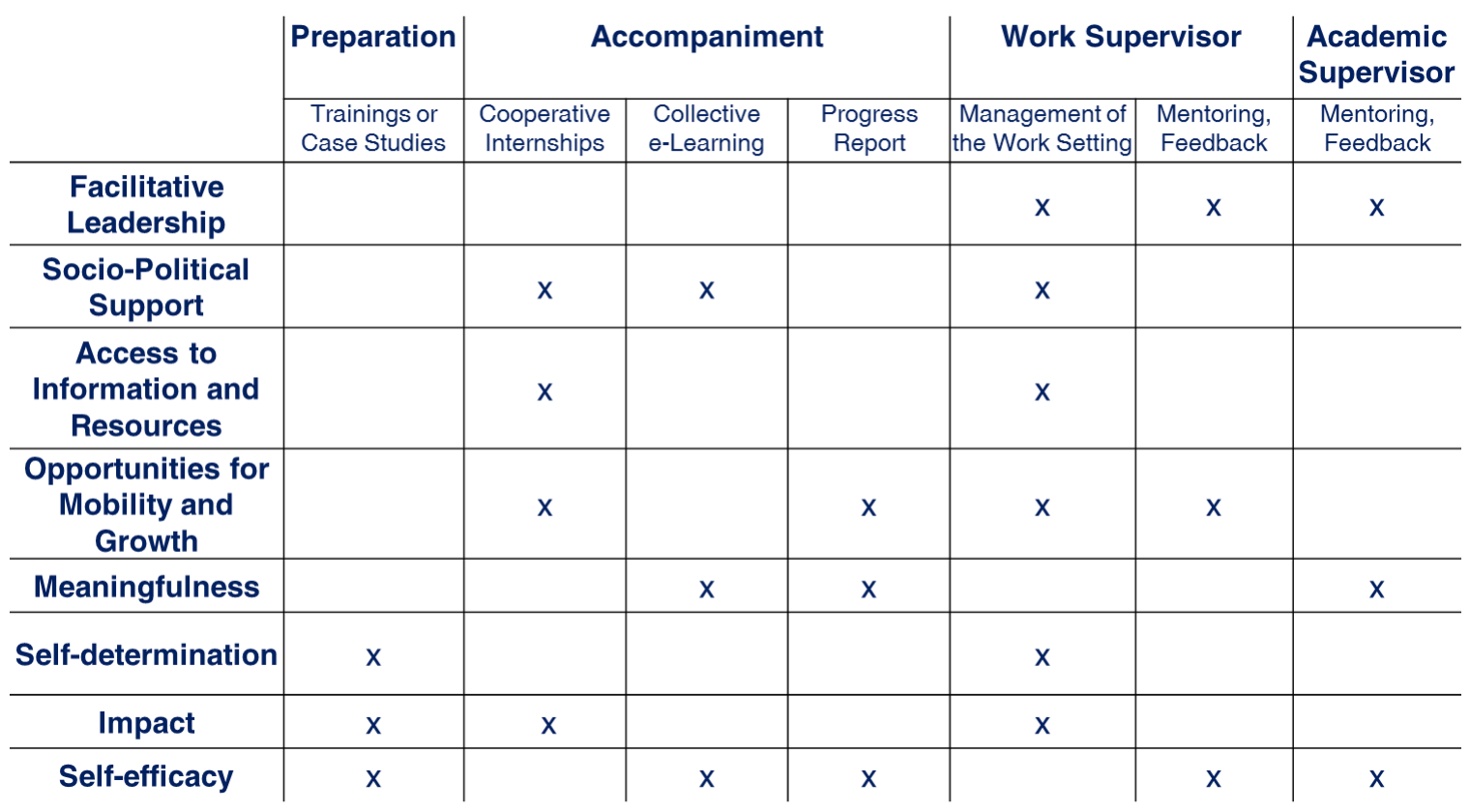




\section{Conclusion}

In this paper, we displayed that employability, which is a central aim of higher education, can be fostered through competence development in WBL settings. We highlighted the question of how this development can be support by the parties involved, namely the individual, the university and the practical partner, in the phases of preparation and accomplishment of internships. We based the answer on the social cognitive theory and empowerment research and were, thereby, able to deduce and systematize influencing factors on competence development leading to an enhanced employability. In doing so, we aimed at proposing an approach that integrates individual and contextual enabling factors of WBL settings. Using internships - the prevalent WBL setting in higher education - we exemplified design implications.

Since there is still a lack of empirical research on how internships can be implemented effectively, it would be beneficial to integrate the considerations on empowering conditions in empirical studies. Lee, McGuiggan and Holland, for instance, call for a prepost approach to specify the conditions that enable the most efficient integration of WBL in higher education [46]. An integration of empowering learning conditions as moderating variables in such an approach would allow the further specification of the mode of operation of WBL settings. Based on that sort of study, the effectiveness of the design of WBL settings could be enhanced.

We particularly recommend action-centred measures to get to the core of the actions and interactions that underpin the conditions, i.e. items describe concrete actions, processes and working conditions when conducting empirical studies. It seems necessary to capture the process and activity character which are necessary on the individual level in order to deal with uncertain situations and with the need for continuous renewal.

Furthermore, there is a need for a shifted focus towards the evaluation of the underlying competence dimensions of employability and how these can be developed. Until now, there has only been a little research on students' competence development in higher education research and, when so, studies often use the descriptions of specific work tasks and their fulfilment for the evaluation [15]. This kind of measurement is questionable, as doing a very specific task does not make visible or only hints at necessary competences, for example, for dealing with complexity to fulfil the task. However, this type of evaluation shows if students, after all, had the possibility to make use of their professional, social and personal skills during their WBL setting. If so, it can be inferred that they also had the opportunity to improve their competences - even if the level of development is still unclear. Additionally, the well- researched mutual relationship between students' self-efficacy and their performance is lacking as it only evaluates performance in terms of the capacity to make use of isolated knowledge and skills in the working context and not competence development [49]. Nevertheless, it can still be assumed that the WBL settings assessed must have had a positive influence on one or more competences, but it is unclear what influenced the development. Further research should, therefore, concentrate on discrete employability enhancing competences related to the isolated influencing factors. In order to do that, we support Baartman and Ruijs' call for longitudinal studies to get deeper insights into students' development of competences, because longitudinal studies particularly shed light onto developmental and learning progressions which both require an evaluation over a period of time [15]. More precisely, we suggest an action-centred evaluation to capture competences which enhance students' employability, as mentioned above. In this way, cross-situational action and problem-solving capabilities can be assessed by the successful and self-organised coping with changing requirements in ambiguous work situations which are a result of problem-solving skills, knowledge and abilities.

\section{References}

[1] M.E. Balta, J.L. Coughlan, and P. Hobson, "Motivations and barriers in undergraduate students' decisions to enrol in placement courses in the UK", Journal of International Education Research, 2012, pp. 399-413.

[2] Bologna Declaration, "Towards the European higher European area. Conference of ministers responsible for higher education in 29 European countries", Bologna, Italy, June 1999.

[3] P. Tynjälä, V. Slotte, J. Nieminen, K. Lonka, and E. Olkinuora, "From university to working life: Graduates' workplace skills in practice", in: P. Tynjälä, J. Välimaa, and G. Boulton-Lewis (Eds.), Higher Education and Working Life - Collaborations, Confrontations and Challenges, Elsevier, Amsterdam, 2006, pp. 73-88.

[4] A. Virtanen, P. Tynjälä, and A. Eteläpelto, "Factors promoting vocational students' learning at work: study on student experiences", Journal of Education and Work, 2014, pp. 43-70.

[5] D. Johnson, "The use of learning theories in the design of a work-based learning course at masters level", Innovations in Education and Training International, 2000, pp. 129-133.

[6] D. Rossin, and T. Hyland, "Group work-based learning within higher education: An integral ingredient for the personal and social development of students", Mentoring and Tutoring, 2003, pp. 153-162. 
[7] A.A. Lado, and M.C. Wilson, "Human resource systems and sustained competitive advantage: A competency-based perspective", Academy of Management Review, 1994, pp. 699-727.

[8] G.M. Spreitzer, "Taking stock: A review of more than twenty years of research on empowerment at work", in: Barling, J., and C.L. Cooper (Eds.), The SAGE Handbook of Organizational Behavior, SAGE Publications Ltd., London, 2008, pp. 54-72.

[9] Bandura, A., Social Foundations of Thought and Action: A Social Cognitive Theory, Prentice-Hall, Englewood Cliffs, NJ, 1986.

[10] Yorke, M., Employability in Higher Education: What It Is - What It Is Not, LTSN Generic Centre, York, England, 2004.

[11] L. Harvey, "Transition from higher education to work", retrieved from:

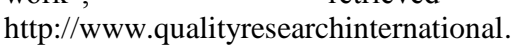

com/esecttools/esectpubs/harveytransitions.pdf, (Accessed: 20 August 2014), 2003.

[12] C.M. van der Heijde, and B.I.J.M. van der Heijden, "A Competence-based and multi-dimensional operationalization and measurement of employability", Human Resource Management, 2006, pp. 449-476.

[13] R. Brooks, and G. Everett, "The predominance of work-based training in young graduates' learning", Journal of Education and Work, 2008, pp. 61-73.

[14] A. Stoof, R.L. Martens, J.J.G. van Merriënboer, and T.J. Bastiaens, "The boundary approach of competence: A constructivist aid for understanding and using the concept of competence", Human Resource Development Review, 2002, pp. 345-365.

[15] L. Baartman, and L. Ruijs, "Comparing students' perceived and actual competence in higher vocational education", Assessment \& Evaluation in Higher Education, 2011, pp. 385-398.

[26] J.S. Shippmann, R.A. Ash, M. Batjtsta, L. Carr, L.D. Eyde, B. Hesketh, J. Kehoe, K. Pearlman, E.P. Prien, and J.I. Sanchez, "The practice of competency modeling", Personnel Psychology, 2000, pp. 703-740.

[17] A. Forrier, and L. Sels, "The concept employability: A complex mosaic", International Journal of Human Resources Development and Management, 2003, pp. 102124.

[18] C. Regehr, G. Regehr, J. Leeson, and L. Fusco, "Setting priorities for learning in the field practicum: A comparative study of students and field instructors", Journal of Social Work Education, 2002, pp. 55-66.

[19] B. Freudenberg, M. Brimble, and C. Cameron, "WIL and generic skill development: The development of business students' generic skills through work-integrated learning", Asia-Pacific Journal of Cooperative Education, 2011, pp. 79-93.
[20] L. Simons, L. Fehr, N. Blank, H. Connell, D. Georganas, D. Fernandez, and V. Petersom, "Lessons learned from experimental learning: What do students learn from a practicum/internship?", Lessons Learned from Experimental Learning, 2012, pp. 325-334.

[21] N. Wilton, "Business graduates and management jobs: An employability match made in heaven?" Journal of Education and Work, 2008, pp. 143-158.

[22] K. Bullock, V. Gould, M. Hejmadi, and G. Lock, "Work placement experience: Should I stay or should I go?", Higher Education Research and Development, 2009, pp. 481-494.

[23] S.M. Matthew, R.M. Taylor, and R.A. Ellis, "Relationships between students' experiences of learning in an undergraduate internship programme and new graduates' experiences of professional practice", Higher Education, 2012, pp. 529-542.

[24] A. Bandura, "Social cognitive theory: An agentic perspective", Annual Review of Psychology, 2001, pp. 126.

[25] Ormrod, J.E., Educational Psychology: Developing Learners, (5th ed.), Glossary, Merrill, Upper Saddle River, N.J., 2006.

[26] F. Luthans, K. Luthans, and B. Luthans, "Positive psychological capital: Going beyond human and social capital”, Business Horizons, 2004, pp. 45-50.

[27] Hackman, J.R., and G.R. Oldham, Work Redesign, Addison-Wesley, Reading, MA, 1980.

[28] P. Dehnbostel, "Learning in work processes Competence development", in: F. Rauner, and R. Maclean (Eds.), Handbook of Technical and Vocational Education and Training Research, Springer, Dordrecht, 2009, pp. 444-453.

[29] A. Al Zahrani, "Psychological empowerment and workplace learning: An empirical study of Saudi Telecom company", Advances in Management, 2012, pp. 37-46.

[30] H. van Mierlo, C.G. Rutte, J.K. Vermunt, M.A.J. Kompier, and J.A.C.M. Doorewaard, "A multi-level mediation model of the relationships between team autonomy, individual task design and psychological well-being", Journal of Occupational and Organizational Psychology, 2007, pp. 647-664.

[31] M. van Grinsven, and M. Visser, "Empowerment, knowledge conversion and dimensions of organizational learning", The Learning Organization, 2011, pp. 378-391.

[32] K.W. Thomas, and B.A. Velthouse, "Cognitive elements of empowerment: An "interpretive" model of intrinsic task motivation," Academy of Management Review, 1990, pp. 666-681.

[33] B.J. Avolio, W. Zhu, W. Koh, and P. Bhatia, "Transformational leadership and organizational commitment: Mediating role of psychological empowerment a moderating role of structural distance", Journal of Organizational Behavior, 2004, pp. 951-968. 
[34] D. Wat, and M.A. Shaffer, "Equity and relationship quality influences on organizational citizenship behaviors: The mediating role of trust in the supervisor and empowerment", Personnel Review, 2005, pp. 406-422.

[35] G.M. Spreitzer, "Psychological empowerment in the workplace: Dimensions, measurement, and validation", Academy of Management Journal, 1995, pp. 1442-1465.

[36] G. Chen, B.L Kirkman, R. Kanfer, D. Allen, and B. Rosen, "A multilevel study of leadership, empowerment, and performance in teams", Journal of Applied Psychology, 2007, pp. 331-346.

[37] A.N. Pieterse, D.V. Knippenberg, M. Schippers, and D. Stam, "Transformational and transactional leadership and innovative behavior: The moderating role of psychological empowerment" Journal of Organizational Behavior, 2010, pp. 609-623.

[38] J.A. Arnold, S. Arad, J.A. Rhoades, and F. Drasgow, "The empowering leadership questionnaire: The construction and validation of a new scale for measuring leader behaviors", Journal of Organizational Behavior, 2000, pp. 249-269.

[39] A.H. Amy, "Leaders as facilitators of individual and organizational learning", Leadership \& Organization Development Journal, 2008, pp. 212-234.

[40] S. Amundsen, and Ø.L. Martinsen, "Empowering leadership: Construct clarification, conceptualization, and validation of a new scale", The Leadership Quarterly, 2014, pp. 487-511.

[41] G.M. Spreitzer, "Social structural characteristics of psychological empowerment", Academy of Management Journal, 1996, pp. 483-504.

[42] J. Almost, and H.K. Laschinger, "Workplace empowerment, collaborative work relationships, and job strain in nurse practitioners", Journal of the American Academy of Nurse Practitioners, 2002, pp. 408-420.

[43] N.J. Foss, P.G. Klein, Y.Y. Kor, and J.T. Mahoney, "Entrepreneurship, subjectivism, and the resource-based view: Toward a new synthesis", Strategic Entrepreneurship Journal, 2008, pp. 73-94.

[44] A. Patrick, and H.K.S. Laschinger, "The effect of structural empowerment and perceived organizational support on middle level nurse managers' role satisfaction", Journal of Nursing Management, 2006, pp. 13-22.

[45] T.J. Cleary, and B.J. Zimmerman, "Self-regulation empowerment program: A school-based program to enhance self-regulated and self-motivated cycles of student learning", Psychology in the Schools, 2004, pp. 537-550.

[46] G. Lee, R. McGuiggan, and B. Holland, "Balancing student learning and commercial outcomes in the workplace", Higher Education Research \& Development, 2010, pp. 561-574.
[47] B.E. Moely, S.H. Mercer, V. Ilustre, D. Miron, and M. McFarland, "Psychometric properties and correlates of the Civic Attitudes and Skills Questionnaire (CASQ): A measure of students' attitudes related to service-learning" Michigan Journal of Community Service Learning, 2002, pp. 15-26.

[48] B.A. De Leng, D.H. Dolmans, R. Jöbsis, A.M. Muijtjens, and C.P. van der Vleuten, "Exploration of an elearning model to foster critical thinking on basic science concepts during work placements", Computers \& Education, 2009, pp. 1-13.

[49] G. Holden, T. Meenaghan, J. Anastas, and G. Metrey, "Outcomes of social work education: The case for social work self-efficacy", Journal of Social Work Education, 2002, pp. 115-133. 